Research Article

\title{
Computational Study of Hot Gas Injection (HGI) into an Ironmaking Blast Furnace (BF)
}

\author{
Zhaoyang $\operatorname{Li}\left(\mathbb{D},{ }^{1,2,3}\right.$ Yixiong Feng, ${ }^{4}$ and Aimin Wang ${ }^{2,5}$ \\ ${ }^{1}$ School of Mechanical Engineering, Zhejiang University, Hangzhou 310027, China \\ ${ }^{2}$ Shandong Iron and Steel Group Co., Ltd., Jinan 250101, China \\ ${ }^{3}$ Center for Simulation and Modelling of Particulate Systems, Southeast University-Monash University Joint Research Institute, \\ Suzhou 215123, China \\ ${ }^{4}$ State Key Lab Fluid Power \& Mechatron System, Zhejiang University, Hangzhou 310027, China \\ ${ }^{5}$ Hengda Fuji Elevator Co., Ltd., Huzhou 313009, China
}

Correspondence should be addressed to Zhaoyang Li; lizhaoyang@shan-steel.com

Received 9 April 2021; Accepted 28 September 2021; Published 14 October 2021

Academic Editor: Jianguo Wang

Copyright (c) 2021 Zhaoyang Li et al. This is an open access article distributed under the Creative Commons Attribution License, which permits unrestricted use, distribution, and reproduction in any medium, provided the original work is properly cited.

Blast furnace (BF) ironmaking is the most important process that produces hot metal (HM) from iron-bearing materials continuously, rapidly, and efficiently. To date, the process is considered to have reached its limit in view of the achieved high process efficiency. In addition, the required high-quality materials are expensive and gradually getting depleted. Hot gas injection (HGI) into the shaft of the BF is an emerging technology recognized potential to solve the aforementioned problems. However, so far, limited information and studies are available, most of which are preliminary studies with regard to the feasibility and aerodynamics of the technology. This hindered the understanding and thus the effective use of this technology. This work presents a numerical study of the multiphase flow, heat, and mass transfer in a BF by a CFD-based process model. The effects of injection composition in terms of $\mathrm{CO}$ and $\mathrm{CO}_{2}$ contents in $\mathrm{HGI}$ are studied first. The calculated results reveal that $\mathrm{HGI}$ of $100 \% \mathrm{CO}$ delivers the best BF performance. Then, the effects of key variables in relation to HGI of $100 \% \mathrm{CO}$, including position, rate, and temperature, are systematically studied. The in-furnace states and overall performance parameters have been analysed in detail. The results show that, through appropriate control of the injection variables, it is possible to achieve improved BF performance including low fuel rate and high productivity, which are considerably affected by the HGI parameters. The BF process model is also demonstrated to be a cost-effective tool in optimizing the key variables of HGI in BF for obtaining optimum process efficiency.

\section{Introduction}

The blast furnace $(\mathrm{BF})$ ironmaking process is the most important technology by which hot metal (HM) is continuously, rapidly, and efficiently reduced from iron-bearing materials [1]. The process heavily relies on the use of carbonaceous materials including coke and pulverised coal (PC) to generate the required energy, which makes up more than $70 \%$ of the energy consumption and production cost in an integrated steelwork. In addition, the necessitated coke is an expensive raw material and gradually getting depleted. Therefore, there is a considerable amount of social and economic concerns over the current $\mathrm{BF}$ ironmaking process.
However, it should be pointed out that, after 200 years of development, the process is recognized to have approached its limit in view of the achieved high process efficiency. Consequently, any considerable amount of fuel reduction only based on the optimization of the traditional $\mathrm{BF}$ is difficult to attempt $[2,3]$.

In recent decades, much attention has been given to the implementation of new technologies on the BF. The new technologies include the hot charge of burden materials $[1,4,5]$, injection of novel matters, such as PC [6], oil [7], natural gas $[8,9]$, and hot gas [10-12], and use of new burden materials including highly reactive coke $[13,14]$ and carbon composite pellet [15]. These technologies have been 
examined at various levels and proved to be useful for improving BF performance. Among these technologies, the hot gas injection (HGI) into the BF is considered useful due to its possible advantages $[1,16]$. The hot gas can be generated from the combustion and reforming of cheaper fuel materials and off-gas within the steelwork, which is more flexible and economical than the combustion of coke and PC. It can be used to intensify the smelting of burden materials and reduce the fuel rate. Compared with fossil fuel injection, HGI avoids the decreased adiabatic flame temperature and the generation of unburnt powders. In addition, HGI can be flexibly implemented at the BF shaft, which avoids the flow of high-speed gas in the low permeability wet zone.

HGI was first introduced by Lance in the 1920s, in which it was used to partly replace the reducing gas generated from combustion of carbonaceous materials in the raceway [17]. After that, little progress was made until middle 1960s. Using an experimental BF (EBF) with a hearth diameter of $4.6 \mathrm{~m}$, HGI of reformed gas at $1000^{\circ} \mathrm{C}$ was tested in Belgium [17]. In late 1970s, Fink employed this technology on an oxygen BF (OBF) to solve the thermal shortage problem [18]. After that, investigations have been intensively performed by various methods such as cold model [19], experimental scale $[11,20,21]$, and commercial scale $[10,22]$ BFs as well as theoretical calculation $[16,18,23-25]$, continuum models $[10,26-28]$, and discrete models $[29,30]$. The EBF (inner volume $3.2 \mathrm{~m}^{3}$ ) [21] and numerical model studies [27] showed that HGI should contain less $\mathrm{CO}_{2} / \mathrm{H}_{2} \mathrm{O}$ due to the strong endothermic effect of carbon solution loss reaction and water gas reaction. The injection position is better to locate at the bottom of the thermal reserve zone in the $\mathrm{BF}$ shaft so that the reaction products $\left(\mathrm{CO}_{2} / \mathrm{H}_{2} \mathrm{O}\right)$ would not undergo severe solution loss $[1,21]$. Besides, the temperature of injected gas should be at around $1000^{\circ} \mathrm{C}[1,19]$ to maintain the temperature profile in the $\mathrm{BF}$. A number of studies showed that HGI improves BF performance in view of decreased coke rate and increased productivity $[21-23,31]$. It was also revealed that the penetration depth of injected gas is in proportion to the volume ratio of injected gas to gas generated from tuyere $[1,19,29]$. By using an EBF, it was shown that shallow penetration of HGI leads to less improved BF performance [11]. Recently, HGI is more frequently employed on the OBF as an enabling technology to address the thermal shortage phenomena in the upper furnace with several typical OBF processes established $[18,22,24,25,32]$. It is also considered as an essential part for realizing the zero-carbon footprint $\mathrm{OBF}$ process through injection of recycled top gas after $\mathrm{CO}_{2}$ capture and storage. With those efforts, HGI has been considered promising and is currently adopted by two world-class projects aiming low carbon production, i.e., ULCOS in the European Union [17] and COURSE50 in Japan [11].

It is clear that the control of the operational parameters of HGI, including injection composition, position, temperature, and rate, has significant impact on the BF performance. However, thus far, a comprehensive study regarding the effects of key operational parameters of HGI on $\mathrm{BF}$ inner states and overall performance indicators is yet available. This hinders the understanding and, therefore, the effective use of the technology. Considering that the ironmaking BF is a complicated multiphase reactor accompanied with high temperature and hazardous conditions, instrumentation is difficult to access its inner states [33]. Also, it is difficult to use theoretical and experimental methods to conduct investigations comparable to a real $\mathrm{BF}$ situation. Alternatively, numerical models are playing an increasingly important role in investigating the BF ironmaking process, see, e.g., the reviews by different investigators [34-37]. Basically, the methods can be either discrete or continuum $[38,39]$. Compared with the discrete models, the continuum models are considered more suitable for process modelling due to its computational efficiency. This work, for the first time, presents a comprehensive numerical study of the effects of HGI on BF performance, with respect to key performance indicators including injection composition, position, temperature, and rate. First, the BF process model used in this is briefly introduced. Then, the effects of HGI compositions in terms of varying $\mathrm{CO}$ and $\mathrm{CO}_{2}$ content are performed. Based on the results, the optimum HGI composition is thus identified to improve BF performance. After that, a systematic study with respect to the key HGI variables including position, rate, and temperature using the identified optimum HGI composition is conducted. Detailed analysis with respect to the flow, heat, and mass transfer as well as thermochemical phenomena in the $\mathrm{BF}$ is carried out for optimizing the injection operational parameters.

\section{Methods}

The present mathematical model is a steady-state, axisymmetric multifluid model. It considers the region of a BF from the slag surface up to the burden surface. The phases considered including gas, solid, and liquid. Each phase in the model is described by separate conservation equations of mass, momentum, and enthalpy, with the key chemical reactions considered. Gas is described by the well-established volume-averaged, multiphase, Navier-Stokes equations [39]. Solids are assumed to be the continuous phase that can be modelled based on the typical viscous model used in multiphase flow modelling $[39,40]$, coupled with the method proposed by Zhang et al. [41] for determination of the deadman boundary. General convection-diffusion equations are applied to describe heat and mass transfer among the different phases. The model is in principle similar to other $\mathrm{BF}$ process models developed by different investigators $[4,40,42-49]$, and moreover, it is able to model the layered burden structure in lumpy zone and cohesive zone (CZ) [40], as well as the varying stockline [40] as well as stock line variation [4]. The details of the model and relevant numerical techniques are available elsewhere $[4,40,41,46,50,51]$ and are not detailed in this paper for brevity. The governing equations, key chemical reactions, and transfer coefficients are summarized in Tables 1 and 2. In this work, the model is modified so that it is able to handle BF with HGI with varying injection composition, position, rate, and temperature within wide ranges. 
TABLE 1: Governing equations of the present model.

\begin{tabular}{|c|c|c|}
\hline \multicolumn{2}{|l|}{ Items } & Description \\
\hline \multicolumn{2}{|c|}{ Mass conservation } & $\nabla \cdot\left(\varepsilon_{i} \rho_{i} \mathbf{u}_{i}\right)=S_{i}$, where $S_{i}=-\sum_{k} \beta_{i, k} R_{k}^{*}$ \\
\hline Momentum conservation & $\begin{array}{l}\text { Gas } \\
\text { Solid } \\
\text { Liquid }\end{array}$ & $\begin{array}{c}\nabla \cdot\left(\varepsilon_{g} \rho_{g} \mathbf{u}_{g} \mathbf{u}_{g}\right)=\nabla \cdot \tau_{g}-\varepsilon_{g} \nabla p+\rho_{g} \varepsilon_{g} \mathbf{g}+\mathbf{F}_{g}^{s} \\
\tau_{g}=\varepsilon_{g} \mu_{g}\left[\nabla \mathbf{u}_{g}+\left(\nabla \mathbf{u}_{g}\right)^{T}\right]-(2 / 3) \varepsilon_{g} \mu_{g}\left(\nabla \cdot \mathbf{u}_{g}\right) \mathbf{I} \\
\nabla \cdot\left(\varepsilon_{s} \rho_{s} \mathbf{u}_{s} \mathbf{u}_{s}\right)=\nabla \cdot \tau_{s}-\varepsilon_{s} \nabla p_{s}+\rho_{s} \varepsilon_{s} \mathbf{g} \\
\tau_{s}=\varepsilon_{s} \mu_{s}\left[\nabla \mathbf{u}_{s}+\left(\nabla \mathbf{u}_{s}\right)^{T}\right]-(2 / 3) \varepsilon_{s} \mu_{s}\left(\nabla \cdot \mathbf{u}_{s}\right) \mathbf{I} \\
u_{l}=0 ; v_{l}=\text { constant }\end{array}$ \\
\hline \multicolumn{2}{|c|}{ Heat and species conservation } & $\begin{array}{c}\nabla \cdot\left(\varepsilon_{i} \rho_{i} \mathbf{u}_{i} \varphi_{i, m}\right)-\nabla \cdot\left(\varepsilon_{i} \Gamma_{i} \nabla \varphi_{i, m}\right)=S_{\phi_{i, m}} \\
\text { If } \varphi_{i, m} \text { is } H_{i, m}, \Gamma_{i}=\left(k_{i} / c_{p, i}\right) \\
S_{\varphi_{i, m}}=\delta_{i} h_{i j} \alpha\left(T_{i}-T_{j}\right)+\eta_{i} \sum_{k} R_{k}^{*}\left(-\Delta H_{k}\right) \\
\varphi_{i, m}=\omega_{g, C O}, \omega_{g, C_{2},}, \omega_{g, H_{2}}, \omega_{g, H_{2} O}, \\
\text { If } \varphi_{i, m} \text { is } \omega_{i, m}, \Gamma_{i}=\rho_{i} D_{i}, S_{\phi_{i, m}}=\sum_{k} \alpha_{i, m, k} R_{k}^{*} \text { where } \begin{array}{l}\varphi_{g, N_{2}}, \omega_{s, F e_{2} O_{3}}, \omega_{s, F e_{3} O_{4}}, \omega_{s, F e O}, \omega_{s, f l u x} \\
\omega_{g}\end{array}\end{array}$ \\
\hline Phase volume fraction & & $\sum_{i} \varepsilon_{i}=1$ \\
\hline State equation & & $p=\sum_{i}\left(y_{i} M_{i}\right) R T_{g} / V_{g}$ \\
\hline
\end{tabular}

The model used in this work is well-developed and has already been validated at different levels. Firstly, it is able to predict the variations of in-furnace states and performance indicators with variation of key operational parameters such as coke rate and blast rate, which were qualitatively comparable with the practical observations of the BF process [4]. Also, the model is demonstrated to be able to well predict the measured results of experimental-scale BF [11, 43], including key performance indicators such as top gas temperature, top gas utilization factor, and productivity, as well as the in-furnace states with regards to layered $\mathrm{CZ}$ structure, gas temperature, and reduction degree. Also, it can precisely describe the overall performance indicators (top gas utilization factor, top gas temperature, and productivity) as well as the key in-furnace state (the position of CZ) in an experimental-scale OBF in China under the conditions both with and without injection of reformed coke oven gas [42]. These results confirm the general applicability of the model over a wide range of operations. For this sake, the model is not further validated and mainly focuses on its application in this work.

\section{Simulation Conditions}

Figure 1 shows the computational domain and an enlarged area demonstrating the representative computational cells. A commercial-scale BF with the inner volume of $5000 \mathrm{~m}^{3}$ is used as the target in this work. Assuming the symmetrical distribution of process variables, only half the $\mathrm{BF}$ is considered in the simulation for computational efficiency. The whole computational domain is divided into $527 \times 129$ nonuniform control volumes under the Cartesian coordinates, which ensures that the mesh is fine enough to precisely capture the complicated multiphase flow in different layers in the lumpy zone and CZ. The refining of the mesh shows that this mesh size gives mesh-independent numerical solutions. Based on a number of numerical trials, the computational parameters have been carefully selected so that results can get convergence within reasonable time and does not suffer from the problem of divergence. The relaxation factor of the velocity field is set at 05 and that of pressure is set at 0.2. The CFD residual is set to be 0.001 . The total iteration number is set at
15000 for the give $\mathrm{BF}$ conditions considering the complexity of the $\mathrm{BF}$ ironmaking process.

The operational conditions for the BF operated without HGI (base case) is listed in Table 3. Burden materials including iron ore, coke, and flux are charged from the furnace top with the ore batch weight of 140 tonnes. A centre-developed radial burden distribution of the ore-to-coke ratio similar to that used by previous researchers $[40,43]$ is adopted in this work. The hot blast is blown into the $\mathrm{BF}$ at the flowrate of $7300 \mathrm{~m}^{3} / \mathrm{min}$ and at the temperature of $1200^{\circ} \mathrm{C}$. Pulverised coal injection (PCI) is implemented at the rate of $1.37 \mathrm{t} / \mathrm{min}$. Corresponding to the blast conditions, the composition, temperature, and flowrate of the reducing gas generated from the raceway are determined based on the local mass and heat balance and used as the inlet conditions of the gas phase, which is also listed in Table 3. This condition is used throughout the simulations for BF both with and without HGI. Note that the water content in the hot blast is negligible under the present condition. Thus, the reducing gas leaving the raceway only consists of $\mathrm{CO}$ and $\mathrm{N}_{2}$. In the first part of this study, HGI with varying $\mathrm{CO}$ and $\mathrm{CO}_{2}$ is used. To facilitate the implementation of top gas recycling and considering the top gas utilization factor is usually around $50 \%$ in a well-operated $\mathrm{BF}[1,3]$, the $\mathrm{CO}$ content in the HGI is gradually increased from $50 \%$ to $100 \%$ at every increment of $10 \%$ to examine the effects of HGI composition on BF performance. The injection temperature is $900^{\circ} \mathrm{C}$, and the injection rate is $1200 \mathrm{~m}^{3} / \mathrm{min}$. The injection position is set at $5.25 \mathrm{~m}$ above the tuyere centre level in the BF. The optimum HGI composition in terms of improving BF performance is then determined. Based on the optimum HGI composition, a parametric study with respect to the injection position, rate, and temperature is performed. Since gas flow in the bosh zone is a major factor limiting the BF productivity and causes unstable phenomena such as flooding $[1,54]$, HGI is only practiced in the BF dry zone (belly and shaft) with varying position. The injection position is ranging from $5.25 \mathrm{~m}$ to $20.25 \mathrm{~m}$ (from the level of tuyere centre) and set up at every increment of $3 \mathrm{~m}$. The injection rate is increased from $0 \mathrm{~m}^{3} / \mathrm{min}$ to $3000 \mathrm{~m}^{3} / \mathrm{min}$ at every increment of $600 \mathrm{~m}^{3} / \mathrm{min}$, and injection temperature is increased from $500^{\circ} \mathrm{C}$ to $1300^{\circ} \mathrm{C}$ at the increment of $100^{\circ} \mathrm{C}$. 


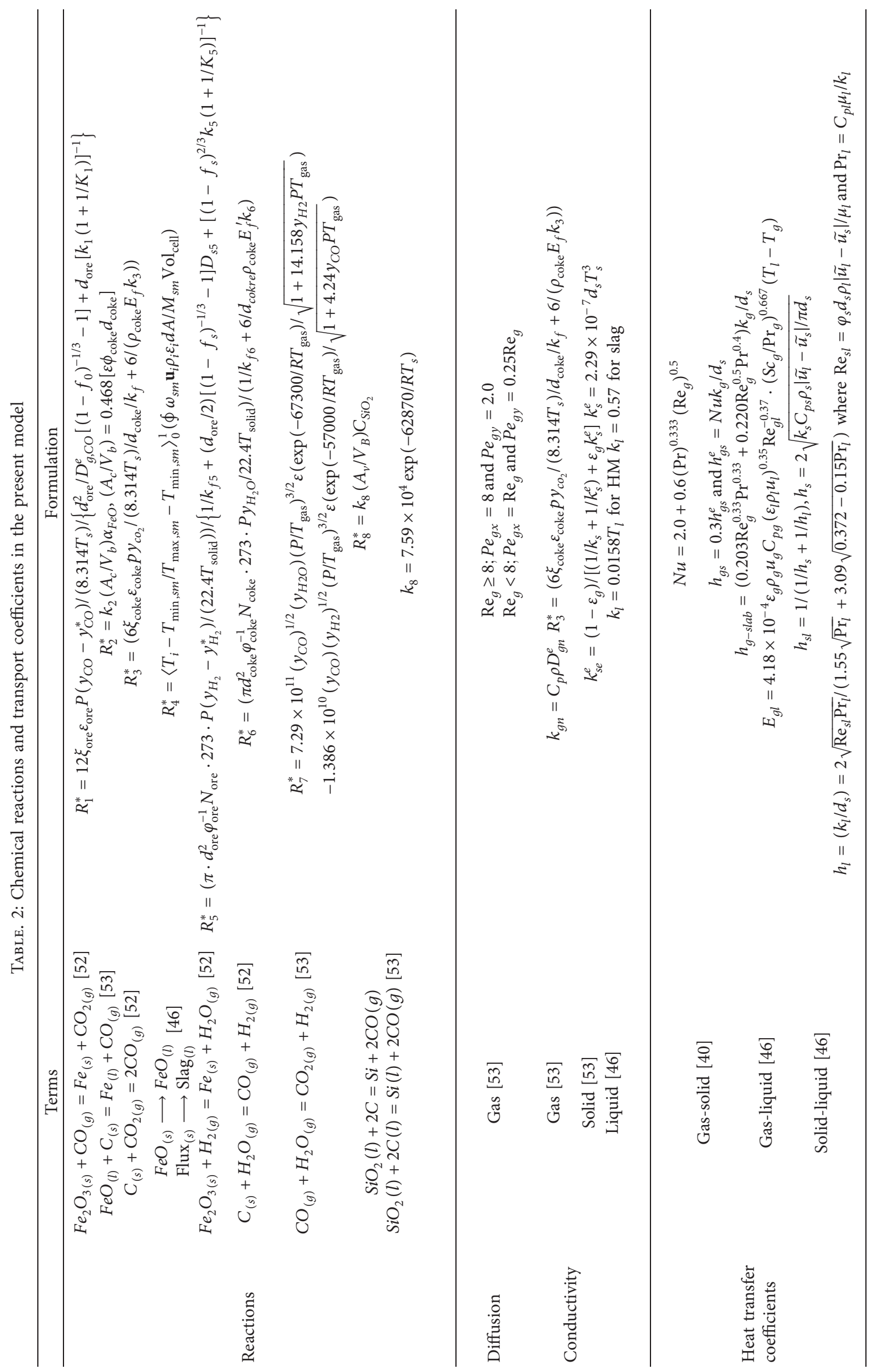




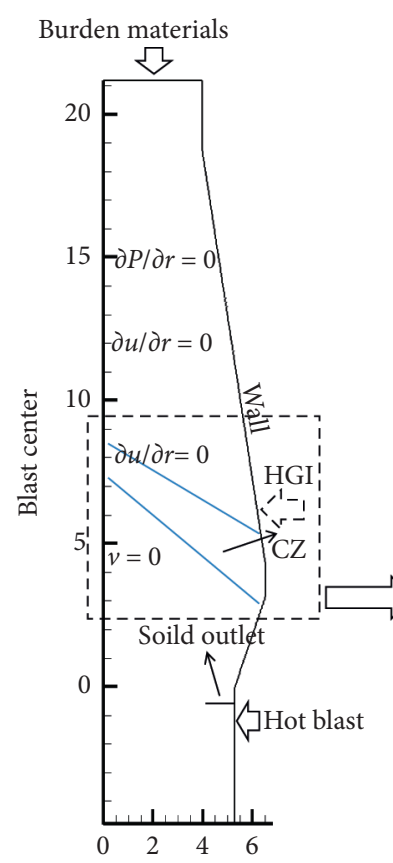

(a)

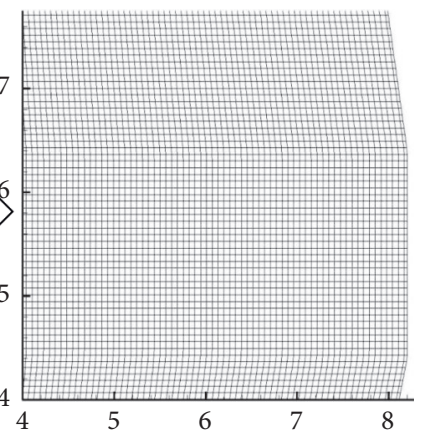

(b)

Figure 1: Schematic illustration of the computational domain (a), and its representative grid arrangement (b).

TABLE 3: Inlet conditions in the base case simulated.

\begin{tabular}{|c|c|}
\hline Variables & Values \\
\hline \multicolumn{2}{|l|}{ Gas: } \\
\hline Inlet velocity $(\mathrm{m} / \mathrm{s})$ & 188 \\
\hline $\begin{array}{l}\text { Inlet gas component (mole } \\
\text { percentage) }\end{array}$ & 38.925 pct $\mathrm{CO} ; 0.0$ pct $\mathrm{CO}_{2} ; 0.0$ pct $\mathrm{H}_{2} ; 0.0$ Pct $\mathrm{H}_{2} \mathrm{O} ; 61.075$ pct $\mathrm{N}_{2}$ \\
\hline Inlet gas temperature $\left({ }^{\circ} \mathrm{C}\right)$ & 2070.6 \\
\hline Top pressure (atm) & 2.0 \\
\hline \multicolumn{2}{|l|}{ Solid: } \\
\hline Ore t.HM & 1.64 \\
\hline Ore components (mass fraction) & $\begin{array}{c}\mathrm{Fe}_{2} \mathrm{O}_{3} \text { 0.6566; FeO 0.1576; } \mathrm{CaO} \text { 0.0652; } \mathrm{MgO} 0.0243 ; \mathrm{SIO}_{2} \text { 0.06; } \mathrm{Al}_{2} \mathrm{O}_{3} \text { 0.0295; } \mathrm{MnO} 0.0061 ; \mathrm{P}_{2} \mathrm{O} 5 \\
\end{array}$ \\
\hline Average ore particle size $(\mathrm{m})$ & 0.018 \\
\hline Coke (kg/t.HM) & 300 \\
\hline Coke components (mass fraction) & C 0.857 ; Ash $0.128 ;$ S $0.005 ;$ H 0.005, N 0.005 \\
\hline Average coke particle size $(\mathrm{m})$ & 0.045 \\
\hline Flux $(\mathrm{t} / \mathrm{t} \cdot \mathrm{HM})$ & 0.0264 \\
\hline Flux components (mass fraction) & $\mathrm{CaO}$ 0.438; $\mathrm{MgO}$ 0.079; $\mathrm{SiO}_{2}$ 0.024; $\mathrm{Al}_{2} \mathrm{O}_{3}$ 0.033; $\mathrm{CO}_{2}$ in $\mathrm{CaO} 0.344 ; \mathrm{CO}_{2}$ in $\mathrm{MgO} 0.082$ \\
\hline Ore voidage & $0.403\left(100 d_{\text {ore }}\right)^{0.14}$ \\
\hline Coke voidage & $0.153 \log d_{\text {coke }}+0.742$ \\
\hline $\begin{array}{l}\text { Average ore/(ore + coke) volume } \\
\text { ratio }\end{array}$ & 0.5923 \\
\hline Burden temperature $\left({ }^{\circ} \mathrm{C}\right)$ & 25 \\
\hline
\end{tabular}

Note that the position and profile of $\mathrm{CZ}$ in a $\mathrm{BF}$ is of major importance in affecting the BF performance and stability $[4,40]$, which also largely determines the lower furnace state. With the same CZ, a BF operated under different conditions could lead to similar flow and thermal conditions at the lower part of the furnace, producing HM with similar qualities [7]. Since the implementation of HGI on a $\mathrm{BF}$ is a novel technology that could introduce much uncertainty, the positions of $\mathrm{CZ}$ in $\mathrm{BF}$ with various HGI operations are kept similar to those in the $\mathrm{BF}$ operation without HGI, to secure a comparable and stable production. This is achieved by gradually adjusting the coke rate at $\mathrm{BF}$ top via a "trial and error" method. In this work, the BF operation without HGI is considered to be in stable operation and is treated as the base case. As an example, Figures 2(a) and 2(b), respectively, show the porosity distributions and enlarged CZ profiles in the BF without HGI and with HGI of $100 \%$ CO both before and after coke 


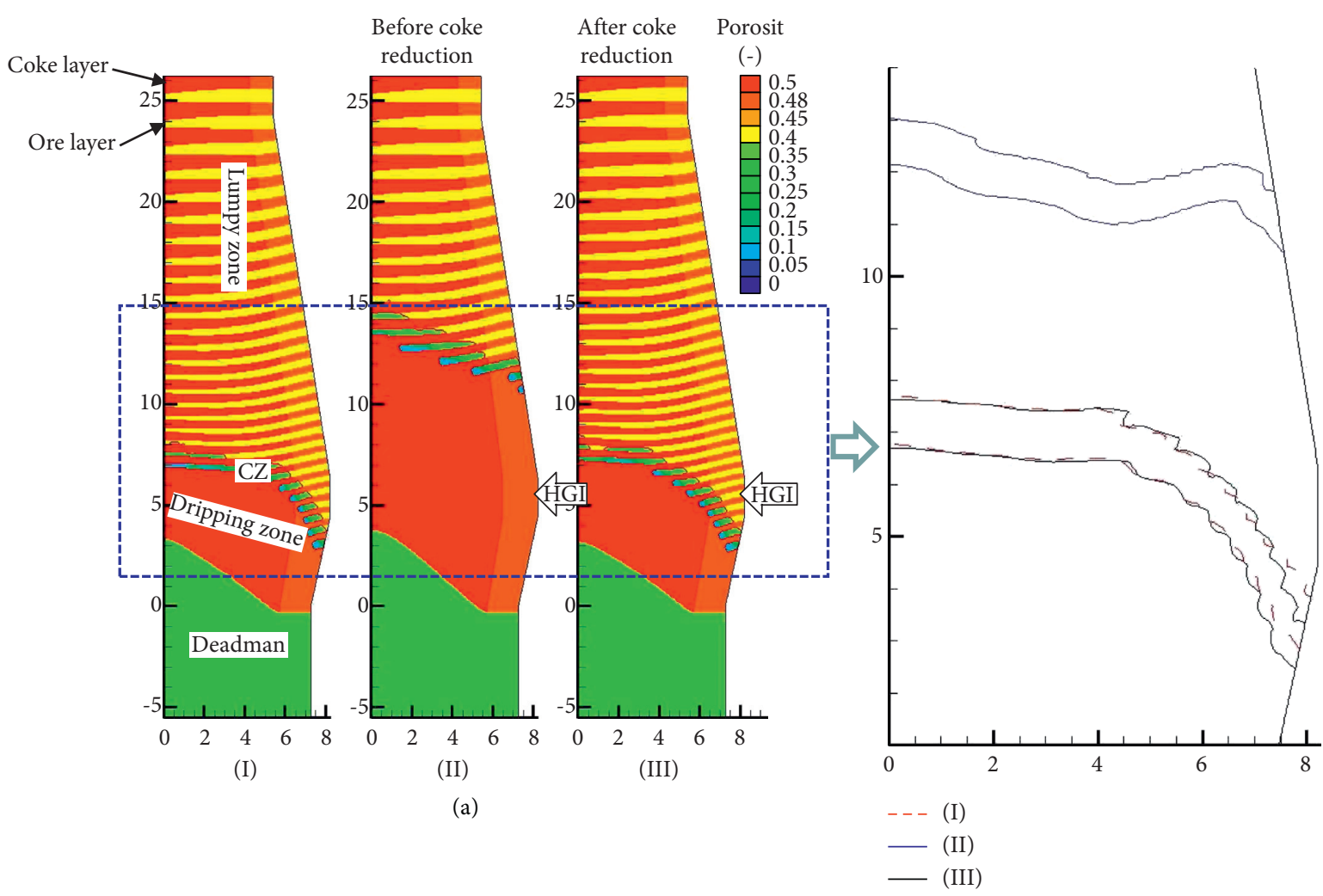

(b)

FIGURE 2: Simulated porosity distribution (a) and CZ (b) for the BF operated without HGI (I), HGI of $100 \%$ CO before coke reduction (II), and after coke reduction (III).

reduction. It is shown that inverse $\mathrm{V}$-shaped $\mathrm{CZ}$ s are obtained in all the operations, which is mainly controlled by the burden distribution pattern and hence porosity distribution $[55,56]$. However, the CZ position rises significantly due to the HGI of $100 \%$ CO. This suggests that there is excessive energy in the BF with HGI of $100 \%$ CO before coke reduction. As seen from Figure 2(b), with proper adjustment of coke rate, similar $\mathrm{CZ}$ profiles and positions can indeed be obtained for the operations with and without HGI. The achieved fuel rate and productivity are calculated and shown in Figure 3 in Section 4.1. Such a method is adopted throughout this work when quantifying the coke rate for a given operation with HGI.

\section{Results and Discussion}

4.1. Effects of HGI Composition. The effects of varying HGI composition are examined first by changing the $\mathrm{CO}$ and $\mathrm{CO}_{2}$ contents. shows the heating-up process in the BF without HGI and with HGI of different compositions. To be clear, only the results for BF without HGI, with HGI of $50 \%$ $\mathrm{CO}+50 \% \mathrm{CO}_{2}$ and HGI of $100 \% \mathrm{CO}$ are shown. In addition to the in-furnace solid temperature for the BF without HGI and with different HGI being represented by flooding, the lines representing the solid temperature for the base operation (BF operated without HGI) are also added to all the cases considered for comparison. As seen from the figure, for all the operations, the solid temperature is higher in the centre region and gradually decreases to the peripheral region, as affected by the centre developed burden distribution. Hence, the temperature profile in the furnace is not significantly affected by HGI but still dominated by the burden distribution patterns $[55,56]$. Compared with the BF without HGI, the solid temperature is higher in the upper furnace with HGI regardless of the injection composition, which suggests that heat energy is supplied to the upper furnace and HGI operations result in more severe cooling losses of heat from the wall [57]. The simulation result is in line with the previous study [23] based on an EBF with injection of hot reformed gas. It is also found that the solid temperature is the highest for BF with $\mathrm{HGI}$ of $50 \% \mathrm{CO}+50 \%$ $\mathrm{CO}_{2}$, which should be attributed to the decreased productivity and leading to a smaller thermal flow ratio in the upper furnace $[1,9,21,42]$.

shows the reduction degree together with the indirect reduction rate of iron ore in the BF without $\mathrm{HGI}$ and with HGI of different compositions. As seen from the figure, the reduction process is improved over the whole cross-sectional area for $\mathrm{HGI}$ of $50 \% \mathrm{CO}+50 \% \mathrm{CO}_{2}$ and injection of $100 \%$ $\mathrm{CO}$ in the furnace top part. This is corresponding to the increased upper furnace temperature that facilitates the indirect reduction rate of iron ore. It can also be seen from the figure that, eventually, all the operations can successfully finish the smelting process of iron ore at similar longitudinal levels. These are similar results as that observed on an EBF in LKAB [11], in which reformed coke oven gas was injected into the lower shaft. The EBF study showed that the 


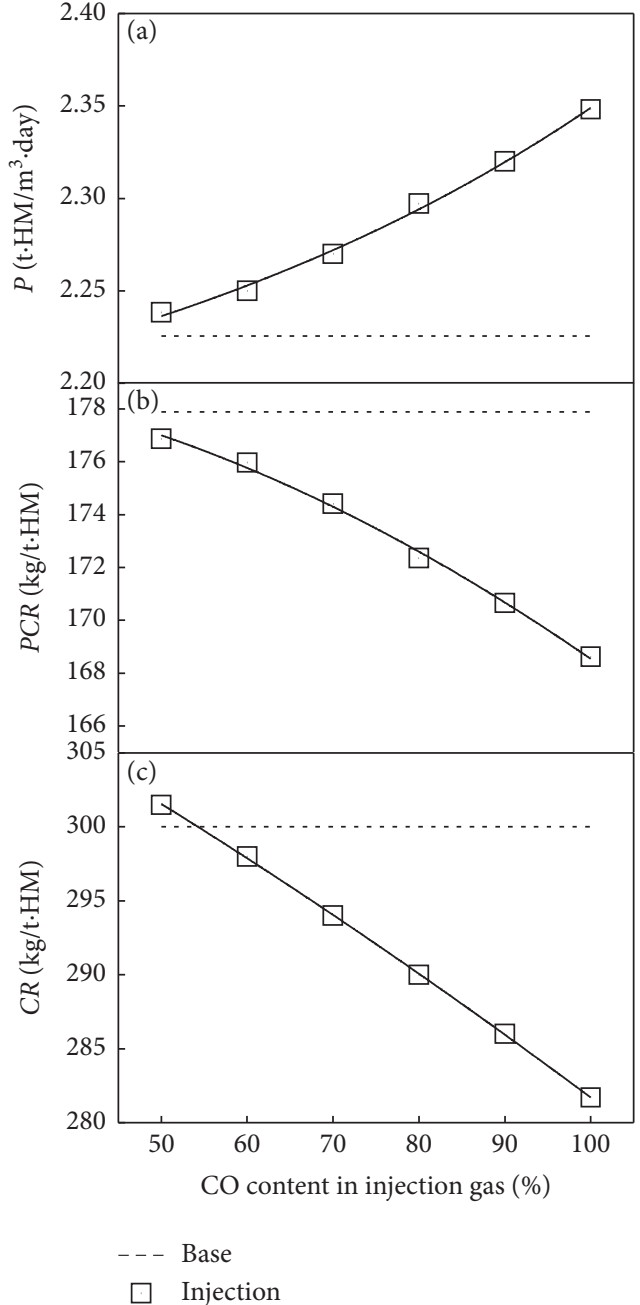

Figure 3: Calculated productivity (P), (a) PCI rate (PCR), (b) and coke rate $(\mathrm{CR})$ (c) for the $\mathrm{BF}$ operated with different $\mathrm{CO}$ contents in HGI.

reduction process is mainly accelerated above the lower injection level and gradually approaches that in the base operation below the injection level. It can be seen from the figure that the composition of injected gas has strong impact on the chemical reactions in the furnace, especially the region near the injection inlet. The indirect reduction of iron ore is intensified in the operation with HGI of $100 \%$ CO. Interestingly, it was also noted that indirect reduction of iron ore was significantly delayed around the injection level and a "hollow" is formed in the operation of BF with HGI of 50\% $\mathrm{CO}+50 \% \mathrm{CO}_{2}$. It is because the local gas composition has already reached the reaction equilibrium and prevents the indirect reduction from further proceeding, while it is the opposite situation for the use of pure $\mathrm{CO}$ that has an effect on lowering down the local $\mathrm{CO}_{2}$-to- $\mathrm{CO}$ ratio. The results for BF with HGI of CO are in line with the simulation [31] and EBF $[1,11]$ results, in which indirect reduction is intensified in the region near the injection inlet. However, it is seen that the region affected by HGI is small. This is due to the insufficient penetration, and therefore, the injected gas mainly flows in the peripheral region, which is in line with the previous studies using EBF [11], cold model [10, 19], and numerical model $[20,42]$.

The coke rate consumed in a BF primarily consists of two parts, including those consumed through chemical reactions (direct reduction of iron ore and carbon solution loss reaction) and those combusted in front of tuyere to supply part of the required heat for the smelting process apart from the energy supplied by fuel materials' injection and external heat energy $[1,4]$. Figures $6(\mathrm{a})$ to $6(\mathrm{c})$, respectively, plot the coke rate consumed through direct reduction $\left(C R_{D R}\right)$, carbon solution loss $\left(C R_{S L}\right)$, and combustion in front of tuyere $\left(C R_{T Y}\right)$ against the $\mathrm{CO}$ content in HGI. As seen from the figure, the coke rate consumed through direct reduction decreases when the $\mathrm{CO}$ content in HGI is increased. This should mainly be attributed to the intensified indirect reduction of iron ore in the region around the injection level, as stated above. Consequently, less iron ore is reduced through direct reduction by coke. It is also seen that only the BF with HGI of $50 \% \mathrm{CO}+50 \%$ $\mathrm{CO}_{2}$ leads to increased coke rate consumed by direct reduction, compared with the base operation without HGI. This is because the iron ore in the peripheral region goes through the "hollow" region where indirect reduction of iron ore is significantly deteriorated. The coke rate consumed through carbon solution loss also decreases as CO content in HGI is increased. This is expected because the reducing gas atmosphere in the furnace is strengthened as more $\mathrm{CO}$ is injected into the $\mathrm{BF}$, which inhibits the solution loss reaction. Figure 6(c) shows that the coke rate consumed through combustion in front of tuyere decreases when the CO content in the injected gas is increased. This is mainly because that the coke-consuming reactions, i.e., direct reduction and carbon solution loss, that are strongly endothermic are restricted, while indirect reduction that is mildly exothermic is intensified when $\mathrm{CO}$ content in the HGI is increased [1]. Thus, the heat requirement in the furnace becomes smaller, and less heat is required to be generated from the combustion of carbonaceous materials in the tuyere region.

The variations of the key performance parameters including productivity $(P), \mathrm{PCI}$ rate (PCR) and coke rate (CR) with $\mathrm{CO}$ content in HGI are calculated by the BF process model and shown in Figures 3(a) to 3(c) respectively. As seen from Figure 3(a), with the increased CO content in HGI, the productivity is increased. This is because the hot blast rate and hence the heat input for a unit time is kept constant for different operations considered in this work. As stated above, the heat required (as indicated by carbonaceous materials consumed through combustion in front of tuyere) for producing unit HM decreases, which means that more iron ore can be smelted into HM and the productivity increases accordingly. This is in line with a number of previous studies based on EBF [11,23] and mathematical model [31]. As shown in Figure 3(b), in accordance with the change of productivity, since the $\mathrm{PC}$ is injected as a constant in unit time, the PCI rate (unit HM basis) is decreased when CO content in HGI is increased. As discussed above, since the coke rate consumed through direct reduction, carbon solution loss, and combustion in front of tuyere all 

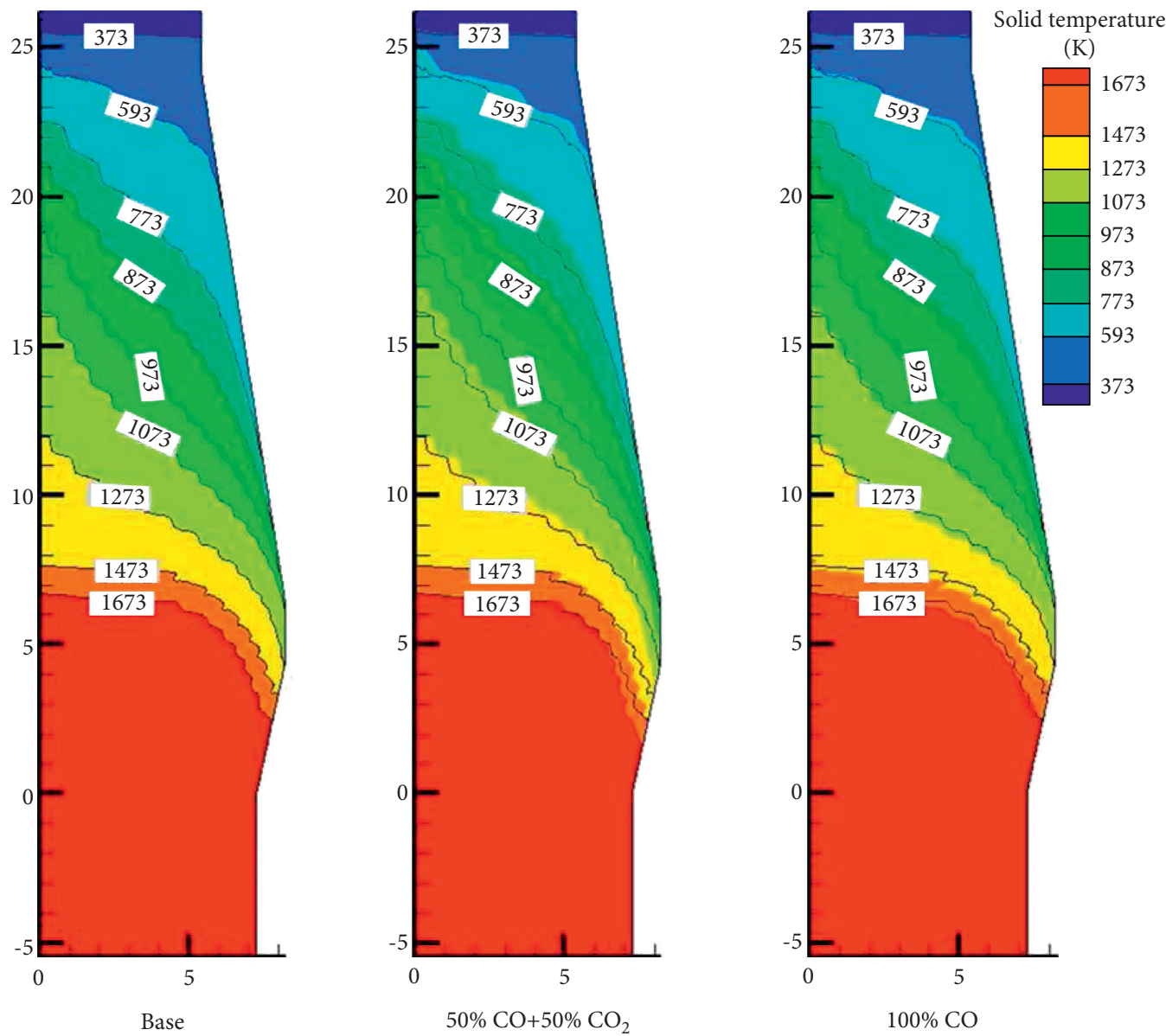

FIgURE 4: Simulated solid temperature distribution for the BF operated without HGI, HGI of $50 \% \mathrm{CO}+50 \% \mathrm{CO}_{2}$, and $\mathrm{HGI}$ of $100 \% \mathrm{CO}$.

decreases with the increased CO content in the HGI, the coke rate decreases consequently. This corresponds to the previous studies by various methods such as EBF $[11,23]$, mathematical model [31], and theoretical model [10], showing that HGI of reducing gas leads to decreased fuel rate. Note that compared with the base operation, all the BFs with injections show reduced coke rates except that with $\mathrm{HGI}$ of $50 \% \mathrm{CO}+50 \% \mathrm{CO}_{2}$, which indicates that the HGI with composition similar to the utilization factor of the top gas of a traditional $\mathrm{BF}$ deteriorates the $\mathrm{BF}$ performance.

The simulated results show that the HGI of $100 \%$ CO presents the best BF performance in view of the significantly increased productivity and decreased coke and PC rate. This is in accordance with the fact that a considerable amount of real BFs are operated with HGI of high $\mathrm{CO}$ contents $[18,22,25,58]$.

4.2. Parametric Study of HGI of $100 \%$ CO into BF. Based on the above results and considering that HGI of $100 \%$ CO can improve the $\mathrm{BF}$ performance, a systematic study with regard to the effects of HGI of $100 \%$ CO into BF is presented in the following section. The key HGI parameters considered include injection position, temperature, and rate. The effects of these parameters on the in-furnace states and performance parameters have been simulated and analysed.
To be succinct and convenience, only representative results are shown for each parameter considered, as the effects of changing these parameters on in-furnace states and performance indicators are monotonous. Note that the operation with the HGI injection rate of $0 \mathrm{~m}^{3}$ is the base operation. Figures 7(a) to 7(c), respectively, show the distributions of solid temperature in BFs operated with HGI of different positions, rates, and temperatures. As seen from the figure, despite of the changing parameters, the solid temperature gradually decreases from the centre region to the peripheral region, which is dominated by the burden distribution in the furnace. This is in line with the previous studies $[55,56]$. The figures show that the upper furnace temperature is increased for BF with HGI of CO regardless of the HGI position, rate, and temperature. The temperature differences between BF with HGI and BF without HGI mainly exist in the region around and above the injection inlet. The temperature differences between $\mathrm{BF}$ with and without HGI are larger when the injection level is higher, especially in the BF top. This is because shorter distance is provided between the injected hot gas and burden materials when the injection level is higher, leading to more intensified heat transfer in the region above the injection level. Also, the increased injection gas rate leads to higher upper furnace temperature. This is easily understood as a higher injection rate leads to larger in-furnace gas flow rate, therefore 

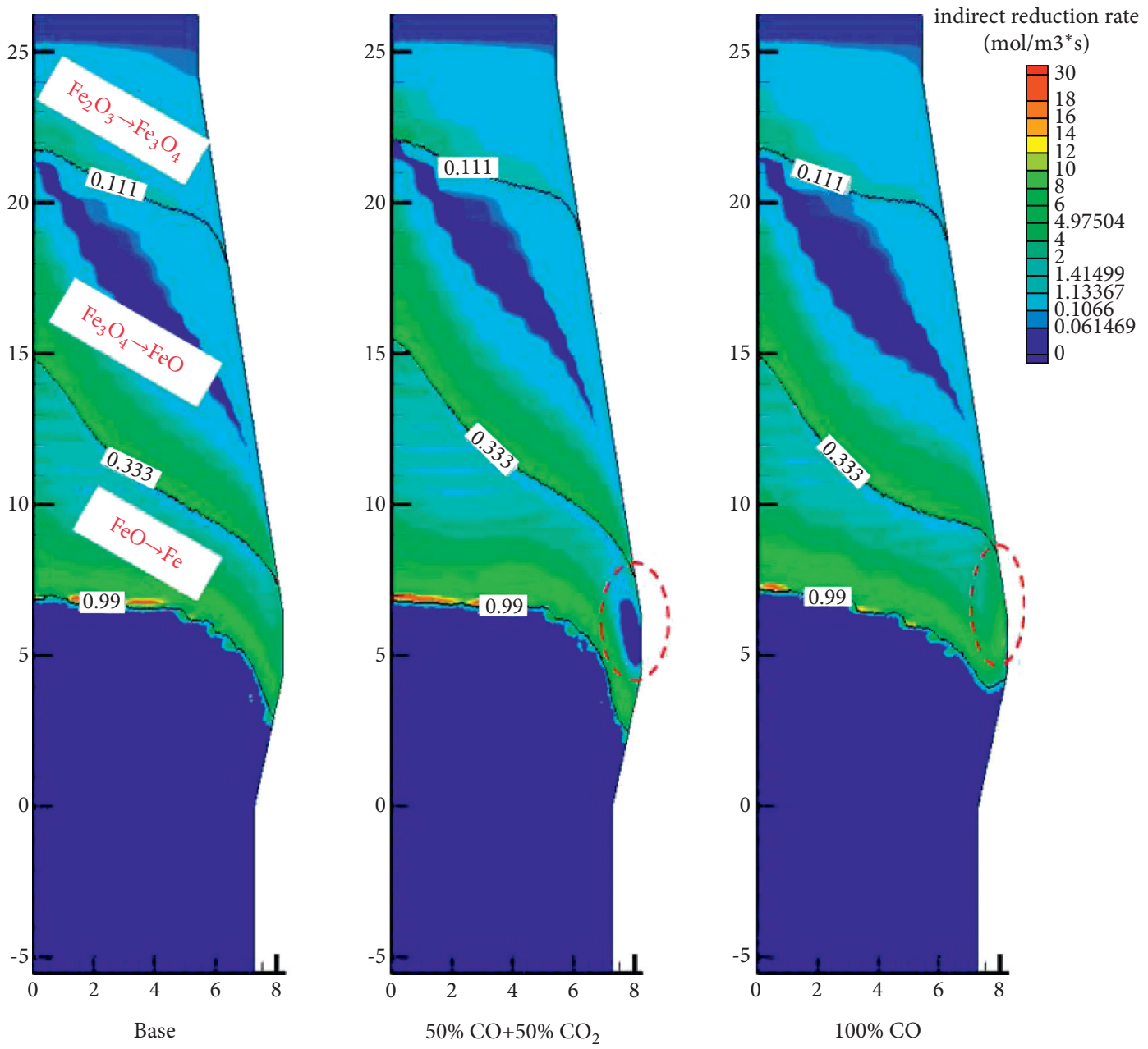

FIGURE 5: Simulated indirect reduction of iron ore and reduction degree for the BF operated without $\mathrm{HGI}, \mathrm{HGI}$ of $50 \% \mathrm{CO}^{-} 50 \% \mathrm{CO}_{2}$, and HGI of $100 \%$ CO.

strengthening the convective heat transfer in the furnace. An increased HGI rate decreases the local temperature near the injection inlet as the HGI temperature is lower than the local burden temperature. Similarly, a decreased HGI temperature is seen to slightly decrease the local temperature in front of the injection inlet within very small region. Generally, the effects of varying HGI parameters on the temperature profile are small. This should be attributed to the fact that the injected gas mainly flows in the peripheral region within a narrow region, which goes through serious heat loss from the wall [23].

Figures 8(a) to 8(c), respectively, show the distributions of the reduction degree of iron ore together with the indirect reduction rate of iron ore in BFs operated with different injection positions, rates, and temperatures. As seen from the figure, compared with the BF operation without HGI, the reduction degree is increased in $\mathrm{BF}$ with HGI regardless of injection position, rate, and temperature since the reducing gas atmosphere in the furnace is strengthened. The improved indirect reduction of iron ore mainly exists in the region near and above the injection level. The reduction degree of iron ore in the BF shaft is more promoted when the injection position is lower as a longer contacting time is provided between injected hot gas and burden materials. Similarly, the increased injection gas rate also improves the indirect reduction in the shaft as the CO concentration in the upper furnace is increased. Also, it was found that a lower injection gas temperature promotes the reduction of iron ore. This is easily understood as the temperature at the injection position is too high that restricts the indirect reduction of iron ore that is an exothermically reaction. Therefore, using HGI at lower temperature helps to alleviate the restriction of indirect reduction. However, it should be pointed out that such effect is small as the temperature profile is not much affected by HGI temperature.

The coke rate consumed through direct reduction, carbon solution loss, and combustion in front of tuyere with $\mathrm{CO}$ injection at different positions, rates, and temperatures are quantified and shown in Figures 9(a) to 9(c), respectively. As seen from Figure 9(a), compared with BF operation without HGI, the coke rate consumed through direct reduction is all reduced when HGI is adopted. It also shows that the amount of the reduced coke rate is larger when the injection position is lower, injection rate is larger, and 


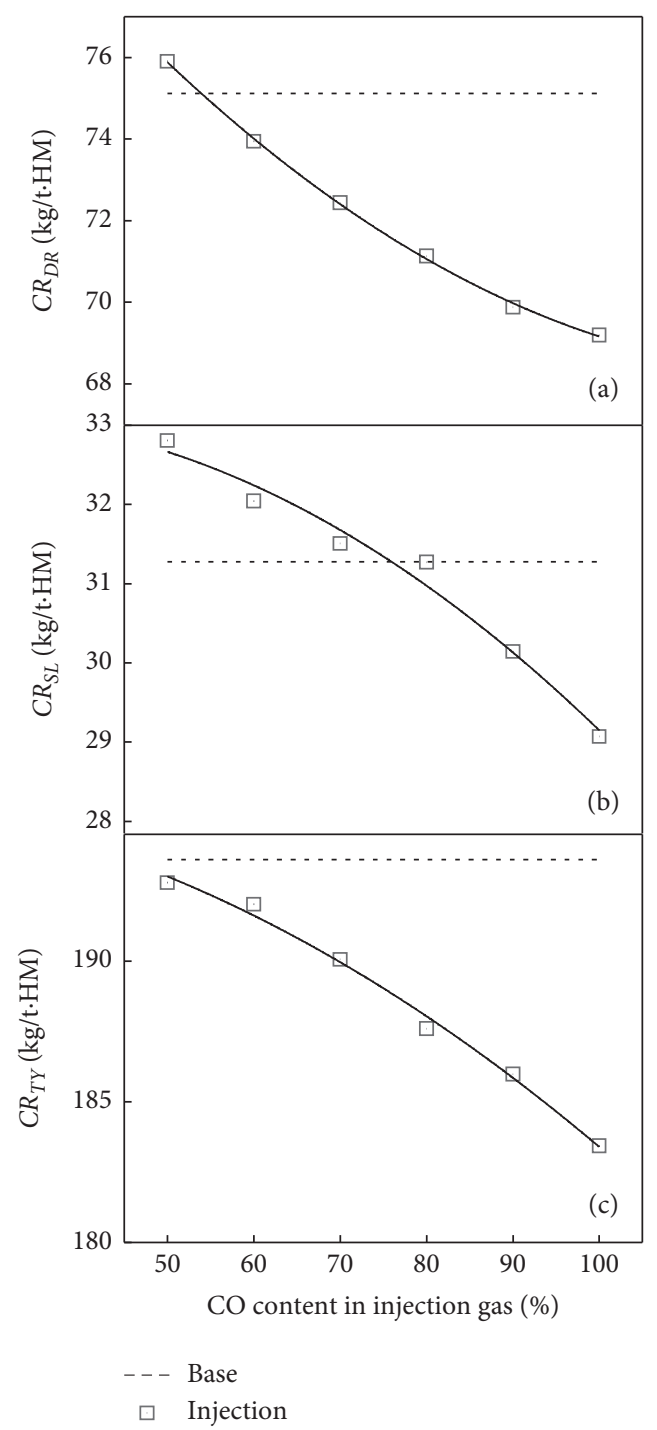

Figure 6: Calculated coke rates consumed through direct reduction $\left(C R_{D R}\right)$, (a) and solution loss $\left(C R_{S L}\right)$, (b) and combusted in front of tuyere $\left(C R_{T Y}\right)$, (c) for the BF operated with different $\mathrm{CO}$ contents in HGI.

injection temperature is lower. Such results are expected because a lower injection level provides a longer contacting distance between injected gas and burden materials. A larger injection rate intensifies the reducing gas atmosphere in the furnace. These both facilitate the indirect reduction in the shaft and inhibit the direct reduction and are in line with theoretical analysis [1]. In the contrary, an increased injection temperature promotes the direct reduction and suppresses the indirect reduction, as the direct reduction being strongly endothermic and the indirect reduction being mildly exothermic $[1,53]$. As seen from Figure 9(b), lower injection position, larger injection rate, and lower injection temperature lead to decreased amounts of coke consumed by the solution loss reaction. This is because the solution loss reaction that being strongly endothermic is more developed in the lower furnace zone where the local temperature is high. As the injection level becomes lower, $\mathrm{CO}$ is injected to the region where solution loss is stronger and has more pronounced impact on suppressing the reaction. Also, the region for HGI to flow in-furnace becomes larger and inhibits the solution loss reaction to a broader extent. An increased HGI rate of $\mathrm{CO}$ decreases the concentration of the reactant $\left(\mathrm{CO}_{2}\right)$ and increases the concentration of the product $(\mathrm{CO})$, which is unfavourable for the reaction thermodynamically $[1,53]$. Conversely, the increased temperature of HGI facilitates the solution loss reaction in the local area. However, the effects are limited since the influenced area is small. Figure 9(c) shows the variations of the coke rate combusted in the tuyere zone with different variables of HGI. As seen from the figure, the amount of the coke rate combusted in the tuyere zone decreases as the injection position becomes lower, injection rate becomes higher, and injection temperature becomes lower. These results are generally in accordance with the variation rates of coke consumed through direct reduction and solution loss, which are strongly endothermic. Interestingly, it was noticed that when the injection position moves down to a certain level, the reacted coke rate does not change much, while the 


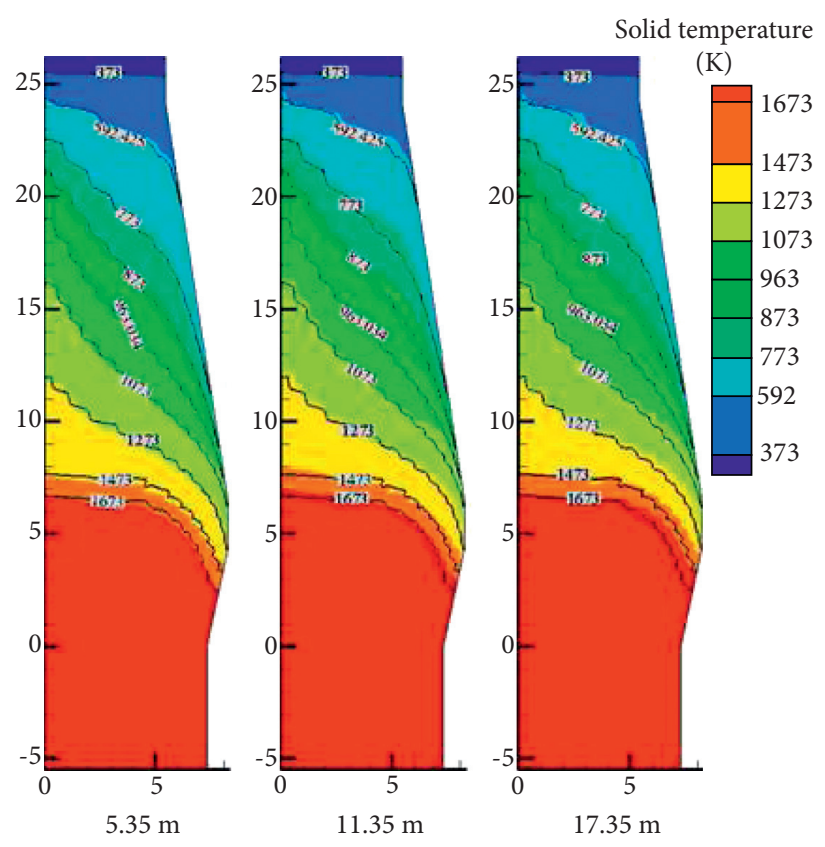

(a)
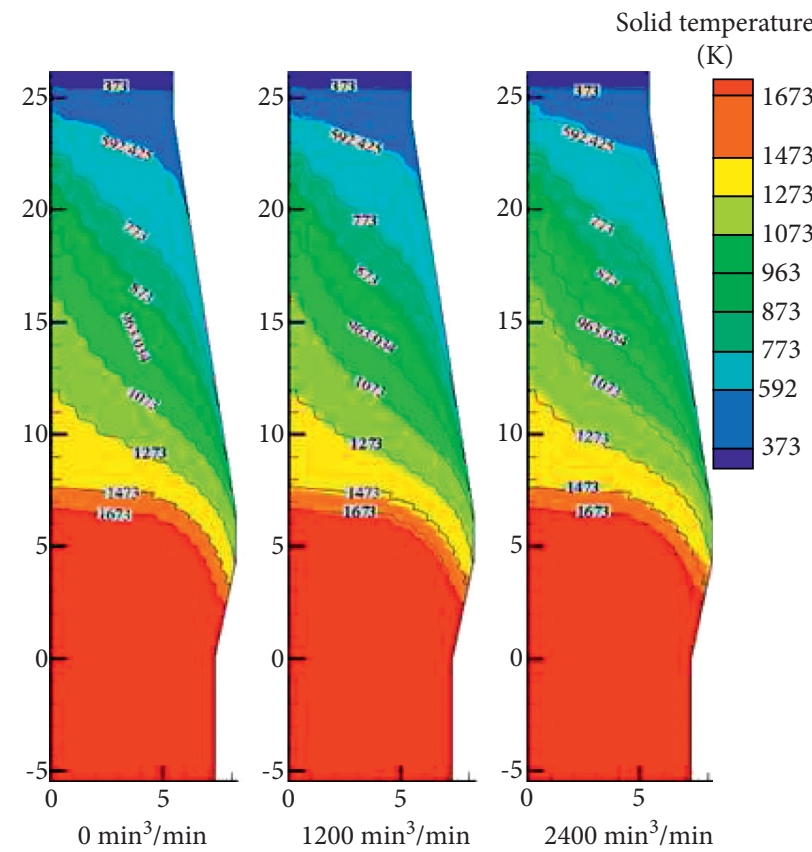

(b)
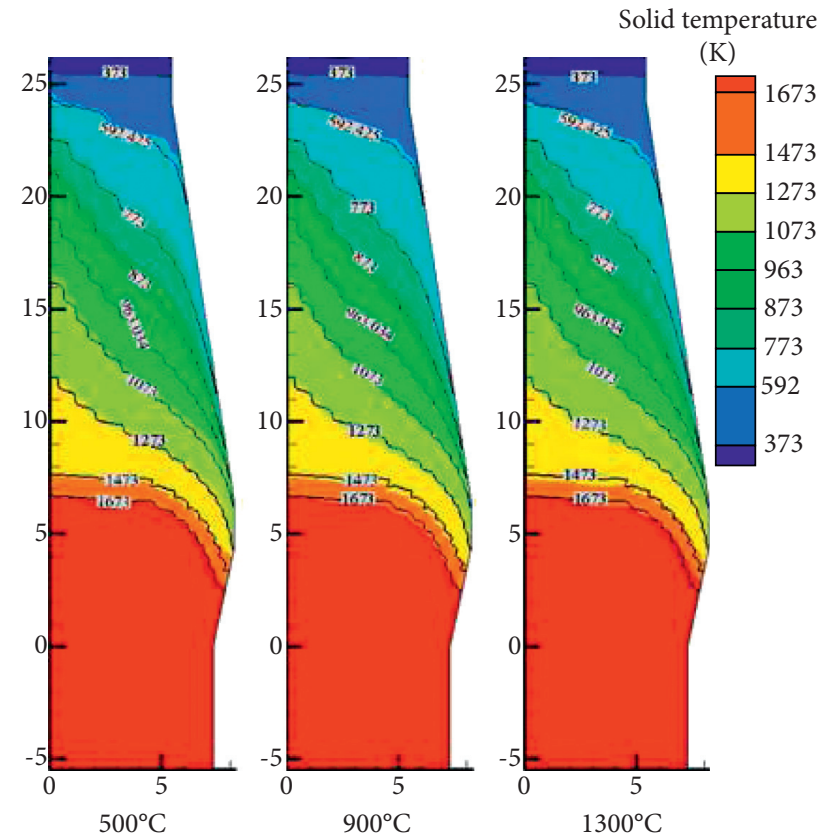

(c)

Figure 7: Simulated distributions of solid temperature for BF with HGI of CO at different positions (a), rates (b), and temperatures (c).

coke rate combusted in the tuyere region still decreases. The decreased coke rate combusted in the tuyere region should mainly be attributed to the improved heat transfer between HGI and burden materials as the contact distance becomes longer. Also it was noted that although HGI with higher temperature brings in more heat energy, the coke rate combusted in the tuyere region still increases. This means that the heat required by the direct reduction and solution loss outweighs that provided by the physical heat of HGI. Additionally, the heat energy brought by HGI suffers from serious heat loss, and little can be transferred to the burden materials.

The effects of key HGI parameters including injection position, temperature, and rate on major performance indicators encompassing productivity, $\mathrm{PC}$ rate, and coke rate are calculated and shown in Figures 10(a) to 10(c), respectively. As seen from the figure, the productivity of the $\mathrm{BF}$ increases when the injection position is lower, injection rate is larger, and injection temperature is lower, which is in accordance with the decreased heat 


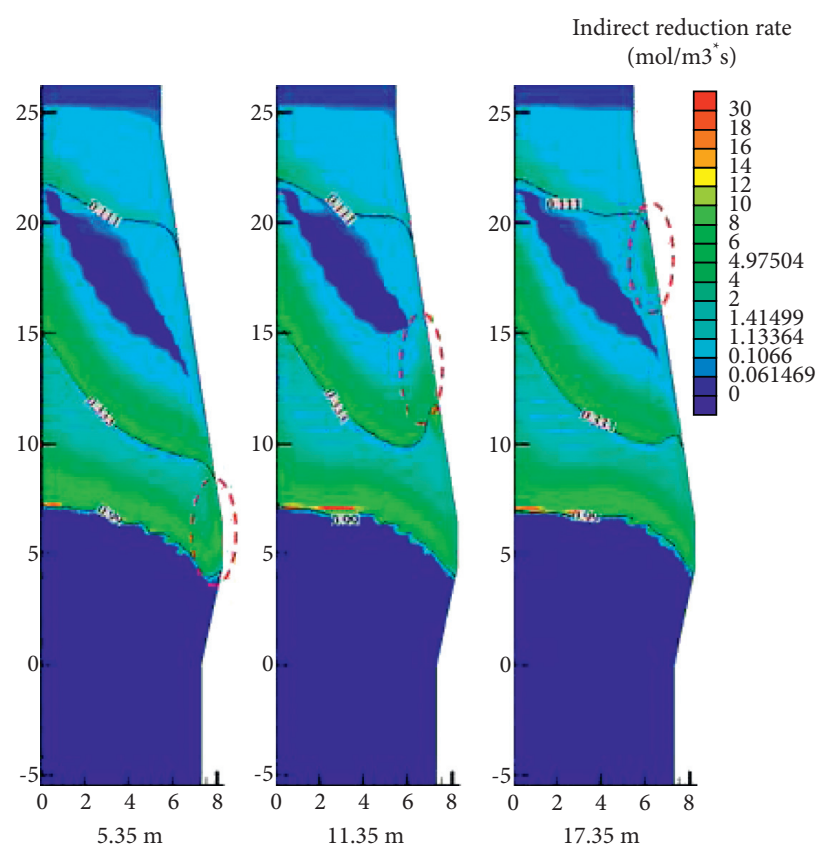

(a)
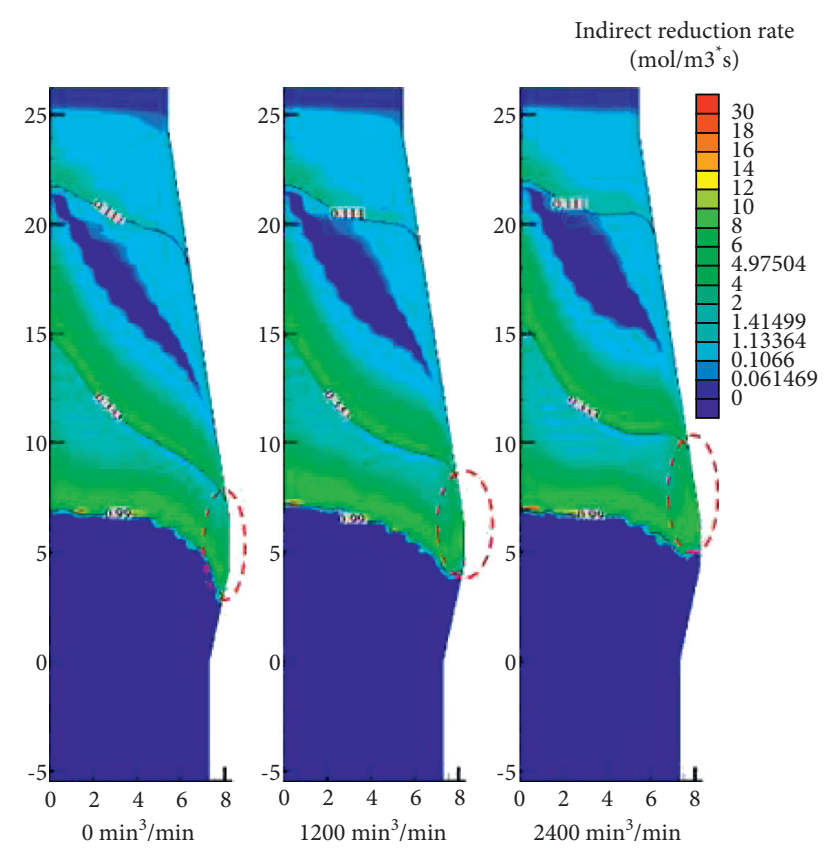

(b)
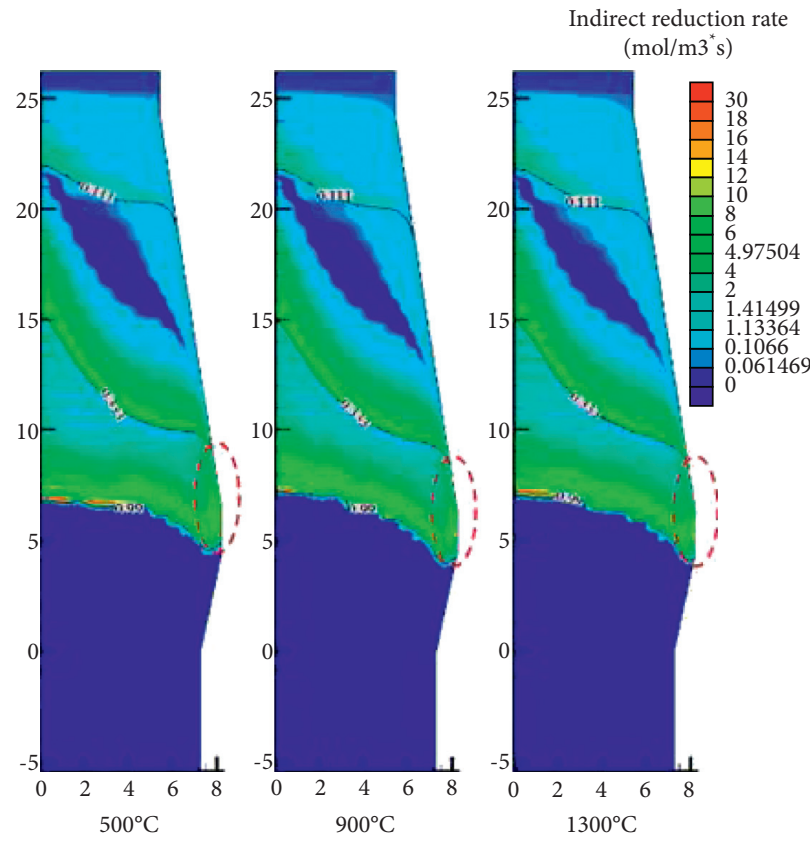

(c)

FIGURE 8: Simulated distributions of the reduction degree for BF with HGI of CO at different positions (a), rates (b), and temperatures (c).

requirement by chemical reactions in the furnace (as reflected by the carbon consumed through strong endothermic reactions including direct reduction and carbon solution loss reflected in Figure 9) under the condition that the heat input in unit times from raceway is kept constant. Corresponding to changes of productivity, since $\mathrm{PC}$ is injected as a constant in unit time, the PCI rate (unit HM basis) increases as the injection position becomes higher, injection rate becomes smaller, and injection temperature becomes higher. It can also be seen from Figure $10(\mathrm{c})$ that the coke rate is lower when the injection position is lower, injection rate is larger, and injection temperature is lower, as a result of the summed coke rate consumed through direct reduction, carbon solution loss, and combustion in front of tuyere. Generally, HGI with lower injection position, larger injection rate, and lower injection temperature is seen to better improve the BF performance in terms of increasing the productivity and decreasing the fuel rate.

4.3. Discussion. The BF ironmaking process is concerned about the utilization of $\mathrm{CO}$ in HGI and its efficiency of replacing the carbonaceous fuel materials (coke and PC). To 


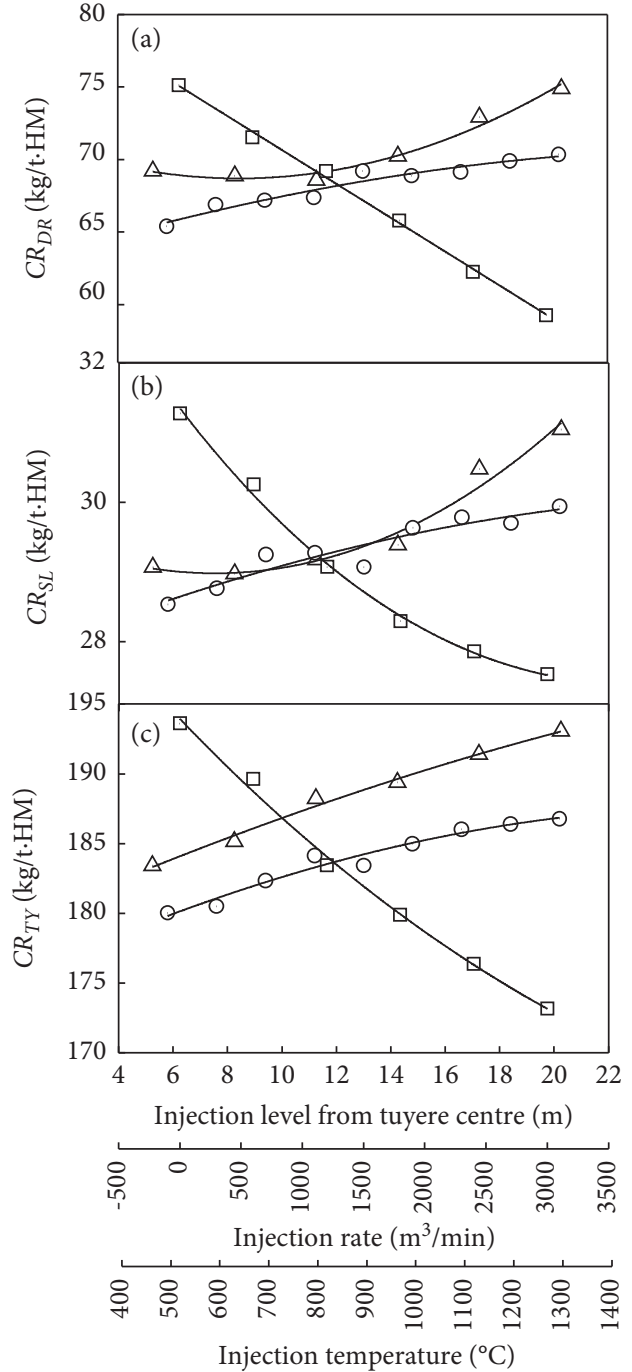

$\triangle$ Injection position
$\square$ Injection rate
$\odot$ Injection temperature

FIGURE 9: Calculated coke rate consumed through direct reduction $\left(C R_{D R}\right)$ (a), solution loss $\left(C R_{S L}\right)(\mathrm{b})$, and combustion in front of tuyere $\left(C R_{T Y}\right)(\mathrm{c})$, for BFs with HGI of $\mathrm{CO}$ at different positions, rates, and temperatures.

be comparable, in this study, a term named "replacement ratio" is used to assess the efficiency of the varying key HGI parameters on replacing the carbonaceous fuel materials by $\mathrm{CO}$ in HGI. It is defined as the ratio of the molar amount of carbon saved from the reduction of coke and PC to the molar amount of CO used in HGI. The effects of injection position, rate, and temperature on the replacement ratio have been calculated and are shown in Figure 11. As seen from the figure, a lower injection position leads to a higher replacement ratio. Such a result is expected as an elongated contacting distance gives longer reduction and heating-up time between iron ore and injected gas. It can also be seen from Figure 11 that optimum values of the injection rate and temperature are found, respectively, at around $1200 \mathrm{~m}^{3} / \mathrm{min}$

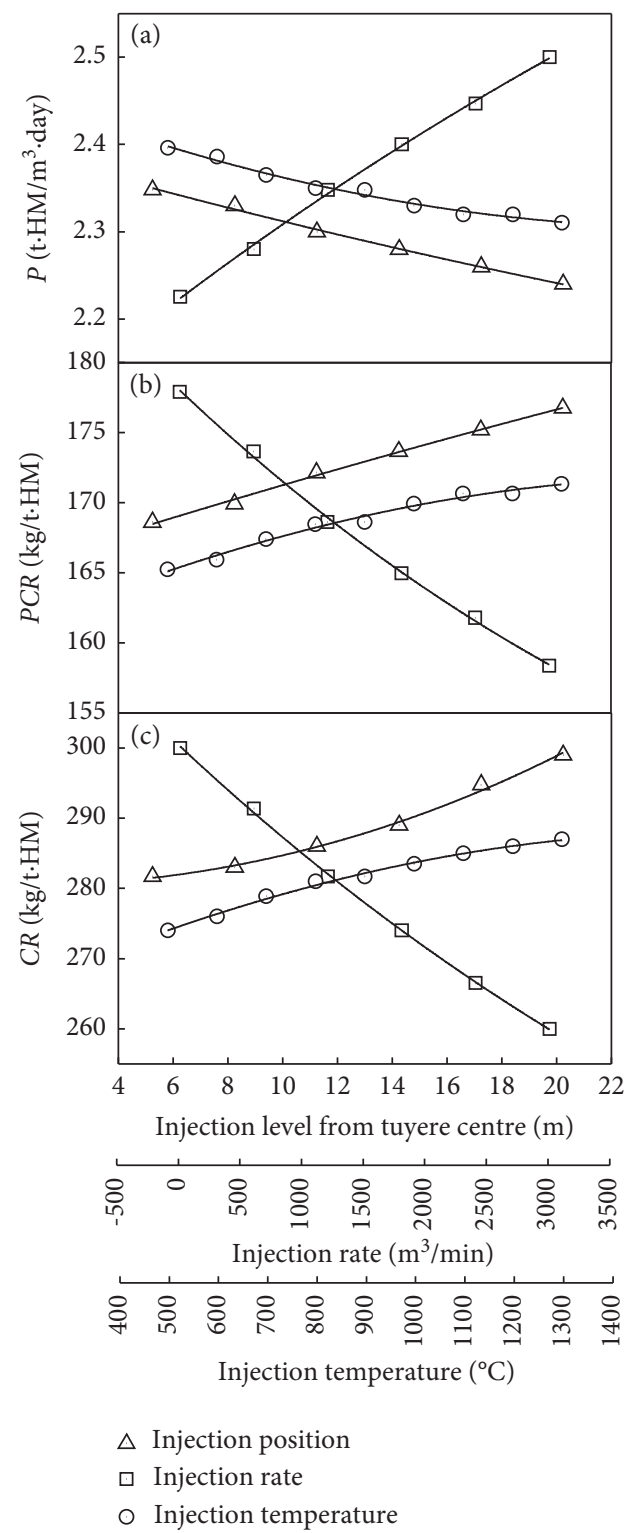

FIgure 10: Calculated productivity (P) (a), PCI rate (PCR) (b), and coke rate (CR) (c), for BFs with HGI of CO at different positions, rates, and temperatures.

and $900^{\circ} \mathrm{C}$. It is explained here. When the injection rate is low and insufficient reactant (CO) and heat energy is provided to the local area, the kinetics of chemical reactions, mainly indirect reduction of iron ore, would not be significantly improved. When the injection rate is too high, the local iron ore is quickly reduced to a large extent and a large portion of the injected gas would not be effectively utilised and goes out of the BF. When injection temperature is low, the decreased local temperature suppresses indirect reduction in kinetics. In the contrary, when injection temperature is too high, the indirect reduction that being exothermic is thermodynamically restricted, which also leads to lower replacement ratio. These are similar results to the previous theoretical analysis [1] and modelling results [42]. Generally, it is noted that the replacement ratio, and thus, the 


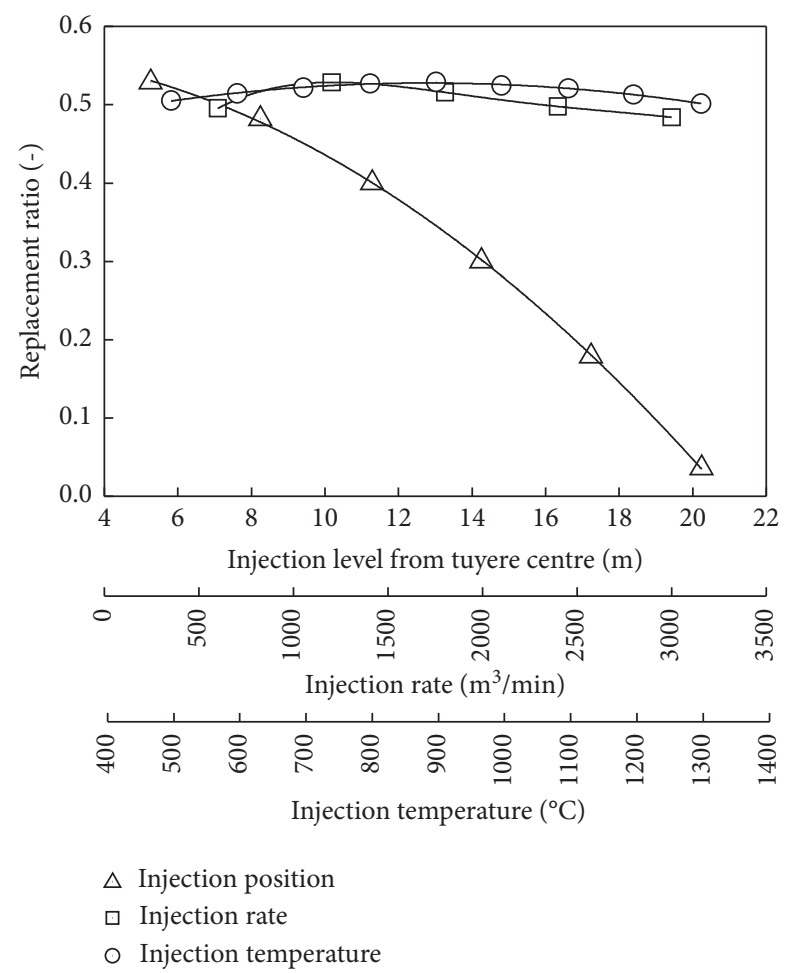

FIGURE 11: Calculated replacement ratio for BFs with $\mathrm{HGI}$ of $\mathrm{CO}$ at different positions, rates, and temperatures.

utilization efficiency of HGI is mostly affected by the injection position compared to the other parameters.

\section{Conclusions}

A well-developed and validated BF process model is modified to study the effects of hot gas injection (HGI) of varying parameters on $\mathrm{BF}$ inner states and performance indicators. The effects of injected gas composition are clarified first. And, this is followed by a systematic study of the effects of the key injection variable in relation to HGI with the optimum composition, with the following findings obtained:

(1) Under the current operational, materials, and geometrical conditions, higher $\mathrm{CO}$ content in HGI leads to better $\mathrm{BF}$ performance in view of increased productivity and decreased fuel rate. HGI of 100\% CO presents the best $\mathrm{BF}$ performance. Compared with the base operation without HGI, the BF performance is worsened when the $\mathrm{CO}_{2}$ concentration in HGI exceeds $50 \%$, in which a "hollow" region is formed where the indirect reduction of iron ore is significantly delayed.

(2) Lower injection position, larger injection rate, and lower injection temperature are found to be favourable conditions for HGI to be employed on the $\mathrm{BF}$, resulting in decreased fuel rates and increased productivities. These are achieved mainly through improved thermochemical behaviours in the BF.

(3) Under the current simulation conditions, optimum injection rate and temperature in term of the best utilization of CO in HGI can be found. The optimum value was established under the kinetics and thermodynamics restrictions. The injection position is found to have the largest impact on the utilization efficiency of CO in HGI.

It should be pointed out that the above conclusions are obtained under the specific conditions considered. The flows and thermochemical states of a commercial-scale BF are extremely complicated, affected by many variables related to the inner profile of furnace as well as operational and raw material conditions. This study mainly demonstrated the possible potential of implementing the HGI technology to improving the $\mathrm{BF}$ performance. Only the effects of the key variable including injection composition, position, rate, and temperature over a wide range are investigated. In the next step, it is necessary to conduct systematic studies to understand the effects of other pertinent variables and their interplays, to further achieve the optimum design and control of BF with HGI referring to different requirements on productivity and energy consumption.

\section{Data Availability}

The DAT data used to support the findings of this study are available from the corresponding author upon request.

\section{Conflicts of Interest}

The authors declare that they have no conflicts of interest.

\section{Acknowledgments}

The authors are grateful to the financial support from China Association for Science and Technology "Young Talent Support Project," Natural Science Foundation of Jiangsu Province (Grant no. BK20180287), and Shandong Provincial Natural Science Foundation, China (Grant no. ZR2020ME107).

\section{References}

[1] A. K. Biswas, Principles of Blast Furnace Ironmaking: Theory and Practice, Cootha Publishing House, Brisbane, Australia, 1981.

[2] C. C. Xu and D. Q. Cang, "A brief overview of low $\mathrm{CO} 2$ emission technologies for iron and steel making," Journal of Iron and Steel Research International, vol. 17, no. 3, pp. 1-7, 2010.

[3] Y. Ujisawa, K. Nakano, Y. Matsukura, K. Sunahara, S. Komatsu, and T. Yamamoto, "Subjects for achievement of blast furnace operation with low reducing agent rate," ISIJ International, vol. 45, no. 10, pp. 1379-1385, 2005.

[4] S. B. Kuang, Z. Y. Li, D. L. Yan, Y. H. Qi, and A. B. Yu, "Numerical study of hot charge operation in ironmaking blast furnace," Minerals Engineering, vol. 63, pp. 45-56, 2014.

[5] T. L. Guo, M. S. Chu, Z. G. Liu, and H. T. Wang, "Numerical simulation on blast furnace operation with hot burden charging," Journal of Iron and Steel Research International, vol. 21, no. 8, pp. 729-736, 2014. 
[6] A. Maki, A. Sakai, N. Takagaki et al., "High rate coal injection of $218 \mathrm{~kg} / \mathrm{t}$ at fuhuyama no 4 blast furnace," ISIJ International, vol. 36, no. 6, pp. 650-657, 1996.

[7] R. Altland, M. K. Beseoglu, T. Broch, W. Lanzer, and K. P. Stricker, "Experience in operating blast-furnaces with high oil injection rates to attain high productivities," Stahl Eisen, vol. 115, p. 83, 1995.

[8] K. S. A. Halim, V. N. Andronov, and M. I. Nasr, "Blast furnace operation with natural gas injection and minimum theoretical flame temperature," Ironmaking \& Steelmaking, vol. 36, no. 1, pp. 12-18, 2009.

[9] M. Jampani, J. Gibson, and P. C. Pistorius, "Increased use of natural gas in blast furnace ironmaking: mass and energy balance calculations," Metallurgical and Materials Transactions B, vol. 50, no. 3, pp. 1290-1299, 2019.

[10] T. Yatsuzuka, K. Nakayama, K. Omori, Y. Hara, and M. Iguchi, "Injection of reducing gas into blast-furnace (FTG process)," Transactions of the Iron and Steel Institute of Japan, vol. 13, no. 2, pp. 115-124, 1973.

[11] S. Watakabe, K. Miyagawa, S. Matsuzaki et al., "Operation trial of hydrogenous gas injection of COURSE50 project at an experimental blast furnace," ISIJ International, vol. 53, no. 12, pp. 2065-2071, 2013.

[12] X. Jiang, J. X. Yu, L. Wang et al., "Distribution of reformed coke oven gas in a shaft furnace," Journal of Iron and Steel Research International, vol. 27, no. 12, pp. 1382-1390, 2020.

[13] S. Nomura, H. Terashima, E. Sato, and M. Naito, "Some fundamental aspects of highly reactive iron coke production," ISIJ International, vol. 47, no. 6, pp. 823-830, 2007.

[14] C. C. Huang, X. J. Ning, G. W. Wang, J. L. Zhang, Z. F. Peng, and H. P. Teng, "Experimental research on semi-coke for blast furnace injection," Journal of Iron and Steel Research International, vol. 28, 2020.

[15] H. M. Ahmed, N. Viswanathan, and B. Bjorkman, "Composite pellets-a potential raw material for iron-making," Steel Research International, vol. 85, no. 3, pp. 293-306, 2014.

[16] A. I. Babich, H. W. Gudenau, K. T. Mavrommatis et al., "Choice of technological regimes of a blast furnace operation with injection of hot reducing gases," Revista de Metalurgia, vol. 38, no. 4, pp. 288-305, 2002.

[17] J. van der Stel, G. Louwerse, D. Sert, A. Hirsch, N. Eklund, and M. Pettersson, "Top gas recycling blast furnace developments for 'green' and sustainable ironmaking," Ironmaking \& Steelmaking, vol. 40, no. 7, pp. 483-489, 2013.

[18] F. Fink, "Suspension smelting reduction-a new method of hot iron production," Steel Times, vol. 36, pp. 398-399, 1996.

[19] H. Nishio and T. Miyashita, "On the top gas recycled reforming process and the injected gas distribution," Tetsu-toHagane, vol. 59, no. 12, pp. 1506-1522, 1973.

[20] Y. Ohno, M. Matsuura, H. Mitsufuji, and T. Furukawa, "Process characteristics of a commercial-scale oxygen blastfurnace process with shaft gas injection," ISIJ International, vol. 32, no. 7, pp. 838-847, 1992.

[21] T. Miyashita, H. Nishio, T. Simotsuma, T. Yamada, and M. Ohotsuki, "Reducing gas injection into furnace stack in an experimental furnace," Tetsu-to-Hagane, vol. 58, no. 5, pp. 608-623, 1972.

[22] M. A. Tseitlin, S. E. Lazutkin, and G. M. Styopin, “A flow-chart for iron making on the basis of 100-percent usage of process oxygen and hot reducing gases injection," ISIJ International, vol. 34, no. 7, pp. 570-573, 1994.
[23] A. Decker and A. Poos, "Injection of reformed gases into blast-furnace stack as a means of reducing coke consumption," Stahl Eisen, vol. 92, p. 1077, 1972.

[24] M. S. Qin, Z. K. Gao, and Y. T. Zhang, "Blast furnace operation with full oxygen blast," Ironmaking Steelmaing, vol. 15, pp. 287-292, 1988.

[25] W. K. Lu and R. V. Kumar, "The feasibility of nitrogen-free blast furnace operation," ISS Transaction, vol. 5, pp. 25-31, 1984.

[26] M. Chu and J. I. Yagi, "Numerical evaluation of blast furnace performance under top gas recycling and lower temperature operation," Steel Research International, vol. 81, no. 12, pp. 1043-1050, 2010.

[27] P. R. Austin, H. Nogami, and J. I. Yagi, "Prediction of blast furnace performance with top gas recycling," ISIJ International, vol. 38, no. 3, pp. 239-245, 1998.

[28] R. B. Smith and M. J. Corbett, "Coal-based ironmaking," Ironmak Steelmak, vol. 14, pp. 49-75, 1987.

[29] S. Natsui, S. Ueda, H. Nogami, J. Kano, R. Inoue, and T. Ariyama, "Penetration effect of injected gas at shaft gas injection in blast furnace analyzed by hybrid model of DEMCFD," ISIJ International, vol. 51, no. 9, pp. 1410-1417, 2011.

[30] S. Natsui, S. Ueda, H. Nogami, J. Kano, R. Inoue, and T. Ariyama, "Dynamic analysis of gas and solid flows in blast furnace with shaft gas injection by hybrid model of DEMCFD,” ISIJ International, vol. 51, no. 1, pp. 51-58, 2011.

[31] M. Chu, H. Nogami, and J. I. Yagi, "Numerical analysis on blast furnace performance under operation with top gas recycling and carbon composite agglomerates charging," ISIJ International, vol. 44, no. 12, pp. 2159-2167, 2004.

[32] Y. Ohno, H. Hotta, M. Matsuura, H. Mitsufuji, and H. Saito, "Development of oxygen blast-furnace process with preheating gas injection into upper shaft," Tetsu-to-Hagane, vol. 75, no. 8, pp. 1278-1285, 1989.

[33] P. Zhou, M. Yuan, H. Wang, and T. Y. Chai, "Data-driven dynamic modeling for prediction of molten iron silicon content using elm with self-feedback," Mathematical Problems in Engineering, vol. 2015, p. 11, Article ID 326160, 2015.

[34] T. Ariyama, S. Natsui, T. Kon, S. Ueda, S. Kikuchi, and H. Nogami, "Recent progress on advanced blast furnace mathematical models based on discrete method," ISIJ International, vol. 54, no. 7, pp. 1457-1471, 2014.

[35] S. B. Kuang, Z. Y. Li, and A. B. Yu, "Review on modeling and simulation of blast furnace," Steel Research International, vol. 89, pp. 1-25, Article ID 1700071, 2018.

[36] S. Ueda, S. Natsui, H. Nogami, J. I. Yagi, and T. Ariyama, "Recent progress and future perspective on mathematical modeling of blast furnace," ISIJ International, vol. 50, no. 7, pp. 914-923, 2010.

[37] J. I. Yagi, "Matehmatical modeling of the flow of 4 fluids in a packed bed," ISIJ International, vol. 33, no. 6, pp. 619-639, 1993.

[38] Z. Q. Li, K. W. Chu, R. H. Pan, A. B. Yu, and J. Q. Yang, "Computational study of gas-solid flow in a horizontal stepped pipeline," Mathematical Problems in Engineering, vol. 2019, Article ID 2545347, 15 pages, 2019.

[39] X. Dong, A. Yu, J. I. Yagi, and P. Zulli, "Modelling of multiphase flow in a blast furnace: recent developments and future work," ISIJ International, vol. 47, no. 11, pp. 1553-1570, 2007.

[40] X. F. Dong, A. B. Yu, S. J. Chew, and P. Zulli, "Modeling of blast furnace with layered cohesive zone," Metallurgical and Materials Transactions B, vol. 41, no. 2, pp. 330-349, 2010.

[41] S. J. Zhang, A. B. Yu, P. Zulli, B. Wright, and U. Tüzün, "Modelling of the solids flow in a blast furnace," ISIJ International, vol. 38, no. 12, pp. 1311-1319, 1998. 
[42] Z. Li, S. Kuang, A. Yu et al., "Numerical investigation of novel oxygen blast furnace ironmaking processes," Metallurgical and Materials Transactions B, vol. 49, no. 4, pp. 1995-2010, 2018.

[43] Z. Li, S. Kuang, D. Yan, Y. Qi, and A. Yu, "Numerical investigation of the inner profiles of ironmaking blast furnaces: effect of throat-to-belly diameter ratio," Metallurgical and Materials Transactions B, vol. 48, no. 1, pp. 602-618, 2017.

[44] K. Yang, S. Choi, J. Chung, and J. I. Yagi, "Numerical modeling of reaction and flow characteristics in a blast furnace with consideration of layered burden," ISIJ International, vol. 50, no. 7, pp. 972-980, 2010.

[45] T. Inada, K. Takatani, K. Takata, and T. Yamamoto, "The effect of the change of furnace profile with the increase in furnace volume on operation," ISIJ International, vol. 43, no. 8, pp. 1143-1150, 2003.

[46] P. R. Austin, H. Nogami, and J. I. Yagi, "A mathematical model for blast furnace reaction analysis based on the four fluid model," ISIJ International, vol. 37, no. 8, pp. 748-755, 1997.

[47] J. A. de Castro, A. J. da Silva, Y. Sasaki, and J. I. Yagi, “A sixphases 3-D model to study simultaneous injection of high rates of pulverized coal and charcoal into the blast furnace with oxygen enrichment," ISIJ International, vol. 51, no. 5, pp. 748-758, 2011.

[48] X. Yu and Y. Shen, "Computational fluid dynamics study of the thermochemical behaviors in an ironmaking blast furnace with oxygen enrichment operation," Metallurgical and Materials Transactions B, vol. 51, no. 4, pp. 1760-1772, 2020.

[49] X. Yu and Y. Shen, "Numerical study of the influence of burden batch weight on blast furnace performance," Metallurgical and Materials Transactions B, vol. 51, no. 5, pp. 2079-2094, 2020.

[50] S. J. Chew, P. Zulli, and A. Yu, "Modelling of liquid flow in the blast furnace. Theoretical analysis of the effects of gas, liquid and packing properties," ISIJ International, vol. 41, no. 10, pp. 1112-1121, 2001.

[51] P. R. Austin, H. Nogami, and J. I. Yagi, "A mathematical model of four phase motion and heat transfer in the blast furnace," ISIJ International, vol. 37, no. 5, pp. 458-467, 1997.

[52] I. Muchi, "Mathematical model of blast furnace," Transactions of the Iron and Steel Institute of Japan, vol. 7, no. 5, pp. 223-237, 1967.

[53] "The Iron and Steel Institute of Japan," Blast Furnace Phenomena and Modelling, Elsevier Applied Science, New York, NY, USA, 1987.

[54] X. F. Dong, T. Pham, A. B. Yu, and P. Zulli, "Flooding diagram for multi-phase flow in a moving bed," ISIJ International, vol. 49, no. 2, pp. 189-194, 2009.

[55] Z. Li, S. Kuang, S. Liu et al., "Numerical investigation of burden distribution in ironmaking blast furnace," Powder Technology, vol. 353, pp. 385-397, 2019.

[56] T. Inada, K. Takata, K. Takatani, and T. Yamamoto, "Effect of blast furnace profile on inner furnace states," ISIJ International, vol. 43, no. 7, pp. 1003-1010, 2003.

[57] T. Ariyama, R. Murai, J. Ishii, and M. Sato, "Reduction of CO2 emissions from integrated steel works and its subjects for a future study," ISIJ International, vol. 45, no. 10, pp. 1371-1378, 2005.

[58] M. Qin and N. F. Yang, "A blast furnace process with pulverized coal oxygen and gas circulation for reduction," Scandinavian Journal of Metallurgy, vol. 15, pp. 138-142, 1986. 